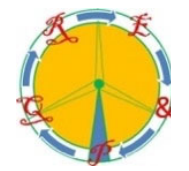

\title{
The decarbonisation of Galicia using renewable marine energy L. Castro-Santos ${ }^{1}$ and A. Filgueira-Vizoso ${ }^{2}$
}

\author{
${ }^{1}$ Universidade da Coruña, Departamento de Enxeñaría Naval e Industrial Escola Politécnica Superior, Esteiro, 15471 \\ Ferrol, Spain, Phone number: +34 881013890, e-mail: 1aura.castro.santos@udc.es \\ ${ }^{2}$ Universidade da Coruña, Departamento de Química, Escola Politécnica Superior, Esteiro, 15471 Ferrol, Spain, Phone \\ number: +34 881013289, e-mail: almudena.filgueira.vizoso@udc.es
}

\begin{abstract}
The objective of this paper is to examine the importance of independent arrays in the offshore renewable energy farms. In this context, several scenarios have been contemplated for a floating offshore renewable energy farm: a farm only using floating wave energy; a farm only using floating offshore wind energy; and a farm composed by floating wave energy and floating offshore wind energy installed in independent arrays. The article proposes a method to calculate the main economic parameters and decide their economic feasibility. A hypothetic offshore renewable energy farm located in the Galicia region (Spain) has been studied as case of study. Results show which of the scenarios has the best economic results. This method is worthwhile to compare different floating offshore renewable energy technologies in economic terms and help in the decision making of this new emerging sector that can help to rebuild Europe in the post-pandemic period.
\end{abstract}

Key words. Floating offshore wind, wave energy, independent array, ocean energy, economic feasibility.

\section{Introduction}

With the growing global concern about the emission of greenhouse gases, different policies and agreements have been developed whose objectives in relatively close periods will significantly reduce the reduction of these pollutants. The Paris agreement [1] establishes that an increase in the global temperature of the planet of $1.5^{\circ} \mathrm{C}$ must be maintained, for this, in 2030, GHG (Greenhouse Gas) emissions must have been reduced by $40 \%$ with respect to the emissions of 1990 and achieve by 2050 a climate neutral Europe. To achieve these objectives it is a priority to change the form of energy production. Fossil fuels are major producers of greenhouse gases and for example in 2020 in the United States $80 \%$ of energy consumption comes from these fuels [2]. In Europe, the outlook is more advantageous [3], the energy consumed during the SARS-CoV-2 pandemic has caused the collapse of coal, renewables have surpassed fossil fuels for the first time, yet to meet European decarbonization targets they should grow threefold. According to the forecasts of the International Energy Agency, wind and solar will reach record growths this year [4]. On the other hand, although renewable energies were already reaching important values, a clear trend is shown between before and after the pandemic, people are acquiring an environmental awareness and are realizing that the planet has a limited capacity to absorb pollution, promoting the use of clean energy both at the user level and at the industrial level [5]

In order to ensure that this trend does not change and that as energy consumption increases, energy consumption is reverted, the EU is making great efforts that are reflected in programs such as the Recovery Plan for Europe, the Next Generation [6], etc. These programs finance projects along different lines, such as digital transformation, reindustrialization and a green pact in favor of clean energy. The main objective of this type of aid is focused on achieving climate neutrality.

To achieve this climate neutrality, it is essential to talk about renewable energies, air, water, soil pollution or consumer products, that is, if we are able to reduce pollution (minimization of GHG) we are achieving all these objectives.

The study we are conducting is based on showing the alternatives in terms of renewable energy.

For years, different devices have been put into operation that supply energy through renewable sources such as the sun $[7,8]$, water [9] or wind [10,11], but in most cases these facilities were located on land. If we take into account that most of the planet is water $(70 \%$ of the planet's surface is water) and that in terrestrial locations there are other facilities that occupy part of these lands, such as cities, cultivation areas and grass, etc. we can see that land-based locations hold great potential for exploiting renewable energy. In addition to this, the characteristics of the wind in the sea are more usable and we can also have systems to extract energy from the waves, among others.

In these two systems, energy extracted from the wind and waves is the one on which this study will be based [1216].

Wind energy is a sector that is widely developed on land but is still in the offshore development phase [17,18], but part of the terrestrial technology is profitable, so the road ahead is long and its development is more imminent. Regarding wave energy, it is a less developed technology and there are numerous prototypes but none are in operation yet. Offshore wind energy differs in how the structure is attached to the seabed. We can have different 
types, when we speak of foundations for shallow waters (less than $30 \mathrm{~m}$ ) we can speak of substructures by gravity[19] or monopile [20]. In the case of greater depths (between 40 and $70 \mathrm{~m}$ ) we have tripod or jacket [21] type substructures and in the case of depths greater than $80 \mathrm{~m}$ we have the TLP [22], semi-submersible [23] or spar [18,24].

Regarding the systems that provide wave energy, the technologies used are by means of oscillating water column (OWC) or by means of oscillating body converters and overtopping converters [25].

OWC are conversion systems with a semisubmerged chamber, keeping a trapped air pocket above a column of water [26]. Waves generate the column to act like a piston, moving up and down and thereby forcing the air out of the chamber and back into it. This continuous movement generates a reversing stream of high-velocity air, which is channelled through rotor-blades driving an air turbinegenerator group to produce electricity [26]. Examples of OWC are: Pico [27], LIMPET, Sakata , Mutriku, Ocean Energy, Sperboy [28], etc.

Oscillating body converters are either floating or submerged [26]. They exploit the more powerful wave regimes that normally occur in deep waters where the depth is greater than $40 \mathrm{~m}$. There are many ways to transform the oscillating movement into electricity: hydraulic generators with linear hydraulic actuators, linear electric generators, piston pumps, etc. [26]. Examples of Oscillating systems are: AquaBuoy [29,30], Wavebob [31], PowerBuoy , Pelamis $[32,33]$, AWS, WaveRoller, Oyster, etc.

The aim of the present paper is to analyse the importance of independent arrays in offshore renewable energy farms. In this sense, three different scenarios will be considered for a floating offshore renewable energy farm: (1) it will be composed only by floating wave energy; (2) it will be composed only by floating offshore wind energy; and (3) it will be composed by floating wave energy and floating offshore wind energy installed in independent arrays.

In the first part of the work, the life cycle of the marine renewable energy farms is analyzed (analyzing the three possibilities: wind energy, wave energy and a combination of both) and the economic parameters necessary to calculate its viability. This analysis is carried out for an offshore farm in northwestern Spain (Galicia) [34]. Once the parameters have been calculated, it can be seen that of the three cases analyzed, the most viable is that of offshore wind energy and the least viable is that of wave energy. This type of analysis will allow us to opt for the type of clean energy that provides the most benefits and that helps regenerate the planet with sustainable energies [35].

\section{Methodology}

The method proposed is based on three steps:

- Step 1: calculate the life-cycle cost of the offshore renewable energy farm.

- Step 2: calculate the energy produced by the farm.

- Step 3: calculate the economic parameters associated to the farm: Net Present Value (NPV), Internal Rate of Return (IRR) and Levelized Cost Of Energy (LCOE).
All of them have been calculated using a software created in Matlab ${ }^{\circledR}$.

Step 1 consists in calculating the life-cycle costs of the renewable energy farm, including design ( $\boldsymbol{C} \mathbf{1}$ and $\boldsymbol{C} 2)$, manufacturing $(\boldsymbol{C 3})$, installing $(\boldsymbol{C 4})$, maintaining $(\boldsymbol{C} 5)$ and decommissioning (C6). These costs are different depending on the type of offshore renewable energy considered. In this sense, regarding the scenarios considered (see case of study), cost such as the manufacturing of the electric cable, the installation process, the maintenance or the dismantling differ depending on the type of farm selected. The total costs (LCS $\left.\boldsymbol{S}_{\text {FOREF }}\right)$ are calculated using equation (1) [36].

$$
L C S_{F O R E F}=C 1+C 2+C 3+C 4+C 5+C 6
$$

Step 2 calculates the energy generated by the farm (E), whose value depends on the scenario considered: equation (2) for scenario 1, equation (3) for scenario 2 and equation (4) for scenario 3. Being $\boldsymbol{E}_{\boldsymbol{w} \boldsymbol{a}}$ the energy generated by the wave energy converters and $\boldsymbol{E}_{\boldsymbol{w} i}$ the energy generated by the floating offshore wind energy structures.

$$
\begin{gathered}
E=E_{w a} \\
E=E_{w i} \\
E=E_{w a}+E_{w i}
\end{gathered}
$$

Finally, Step 3 calculates the economic parameters linked to an offshore renewable energy farm such as the $\boldsymbol{N P V}$ (see equation (5)), the $\boldsymbol{I} \boldsymbol{R} \boldsymbol{R}$ (see equation (6)) and the LCOE (see equation (7)). Being: $\boldsymbol{I}_{\mathbf{0}}$ the initial investment, $\boldsymbol{C F}_{\boldsymbol{n}}$ the cash flow in year $\boldsymbol{n}, \boldsymbol{r}$ the discount rate, $\boldsymbol{N}_{\text {farm }}$ the life-cycle of the farm, $\boldsymbol{E}_{\boldsymbol{n}}$ energy generated in year n.

$$
\begin{gathered}
N P V=-I_{0}+\sum_{n=1}^{N_{\text {farm }}} \frac{C F_{n}}{(1+r)^{n}} \\
0=-I_{0}+\sum_{n=1}^{N_{\text {farm }}} \frac{C F_{n}}{(1+I R R)^{n}} \\
L C O E=\frac{\sum_{n=0}^{N_{\text {farm }}} \frac{L C S_{F O R E F_{n}}}{(1+r)^{n}}}{\sum_{n=0}^{N_{\text {farm }}} \frac{E_{n}}{(1+r)^{n}}}
\end{gathered}
$$

The project will be economically feasible for low LCOE, NPV positive and IRR lower than the discount rate.

\section{Case of study}

Spain has three important offshore areas in terms of offshore wind resource: Galicia, Andalucía and Canary Islands [37]. The present paper will analyse the Galicia region (see Fig. 1), whose strategic location in terms of shipbuilding infrastructure [38] gives a great value to this study. 


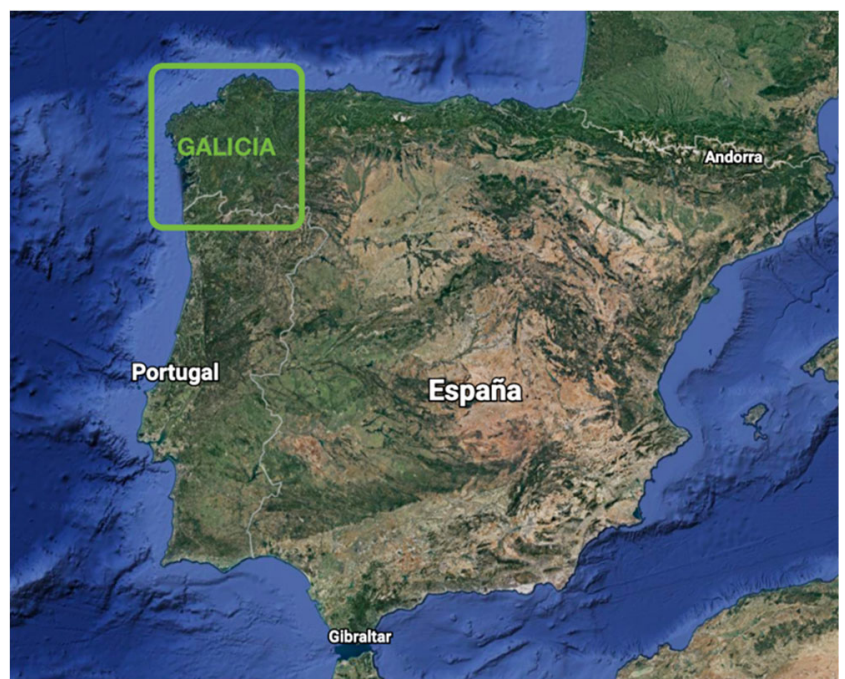

Fig. 1. Location selected.

The total power considered for the farm of study is 500 MW.

Moreover, three scenarios will be studied regarding the type of offshore renewable energy farm (see Table I).

Table I. - Scenarios studied
\begin{tabular}{|c|c|c|c|}
\hline SCENARIO & 1 & 2 & 3 \\
\hline ENERGY & \multirow{2}{*}{ Waves } & $\begin{array}{c}\text { Offshore } \\
\text { Wind }\end{array}$ & $\begin{array}{c}\text { Waves + Offshore } \\
\text { Wind IA }\end{array}$ \\
RESOURCE &
\end{tabular}

Scenario 1 considers a farm composed only by floating wave energy. The wave energy converter selected is Pelamis [39], which power is $0.75 \mathrm{MW}$ per unit.

Scenario 2 takes into account a farm composed only by floating offshore wind energy. The offshore wind structure selected is the WindFloat [40], which unitary power is 5.075 MW. It has a length of $76 \mathrm{~m}, 6$ mooring lines per platform and $10 \mathrm{~m}$ of draft.

Scenario 3 analyses the use of floating offshore co-located structures [41] using independent arrays (IA) of floating wave energy converters and floating offshore wind devices.

Finally, a supposed future electric tariff of $190 € / \mathrm{MWh}$, a capital cost of $8 \%$ and a life-cycle for the farm of 20 years were taken into consideration.

\section{Results}

\subsection{SCENARIO 1}

Considering only wave energy, results go: from $-183.71 \%$ to $-110.36 \%$ for IRR (see Fig. 2), from $-3,926 \mathrm{M} €$ to $-1,895$ $\mathrm{M} €$ for NPV (see Fig. 3) and from 759.25 €/MWh to 1,076 $€ / \mathrm{MWh}$ for LCOE (see Fig. 4). Therefore, for the tariff considered, floating offshore wave energy will not be economically feasible for all the regions considered because their NPV is negative and their IRR is lower than the capital cost.

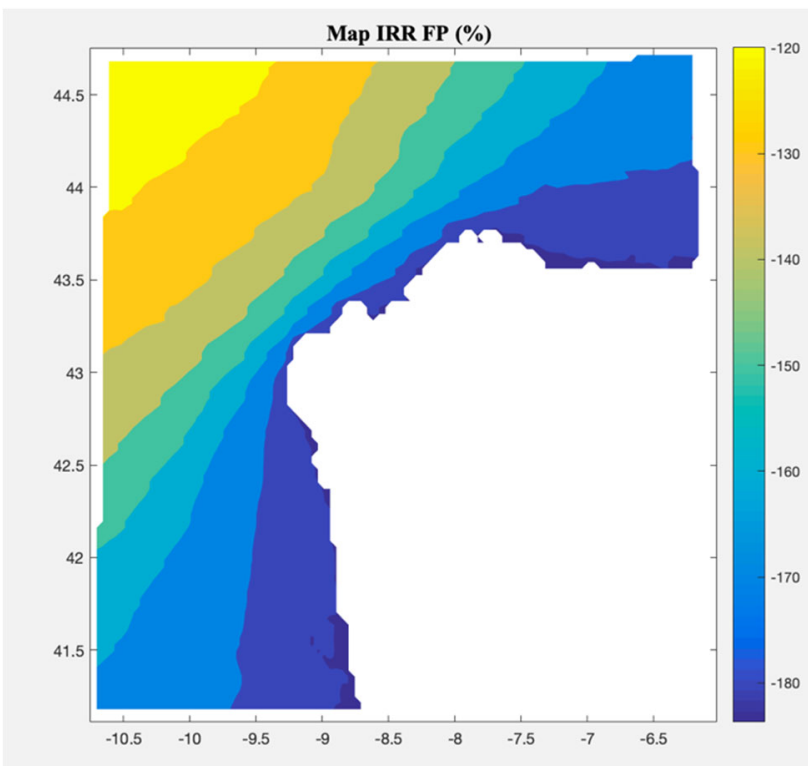

Fig. 2. IRR for Scenario 1.

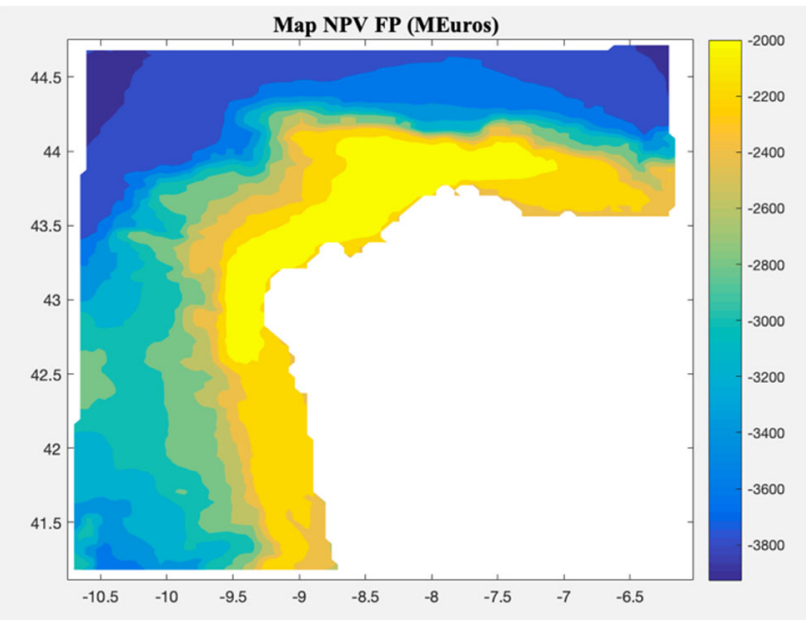

Fig. 3. NPV for Scenario 1.

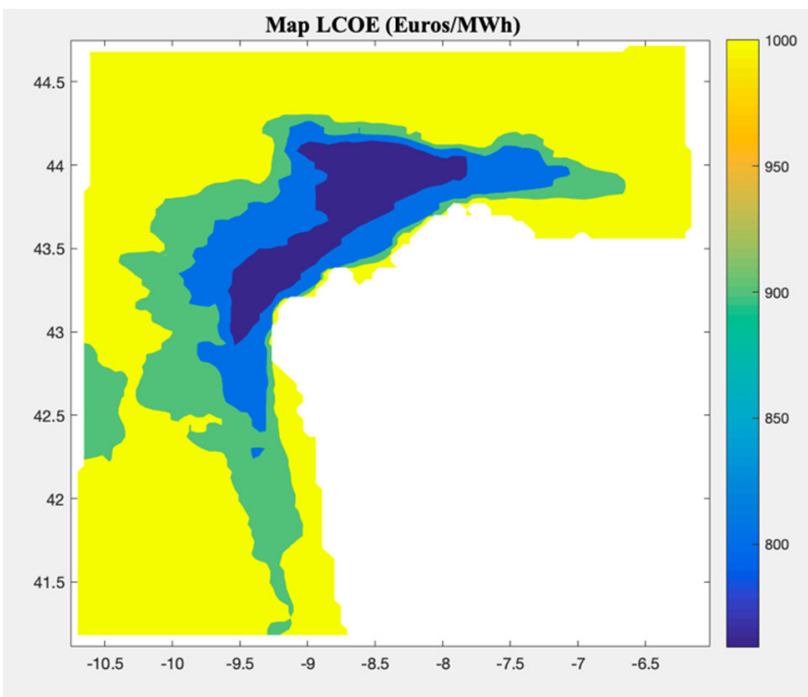

Fig. 4. LCOE for Scenario 1.

\subsection{SCENARIO 2}

Considering only floating offshore wind energy, results go: from $-24.39 \%$ to $22.21 \%$ for IRR (see Fig. 5), from 1,035 M€ to 1,376 M€ for NPV (see Fig. 6) and from 92.69 
$€ / M W h$ to $765.81 € / M W h$ for LCOE (see Fig. 7). Therefore, for the tariff considered, floating offshore wind energy will be economically feasible for some regions where NPV is positive and where IRR is higher than the capital cost.

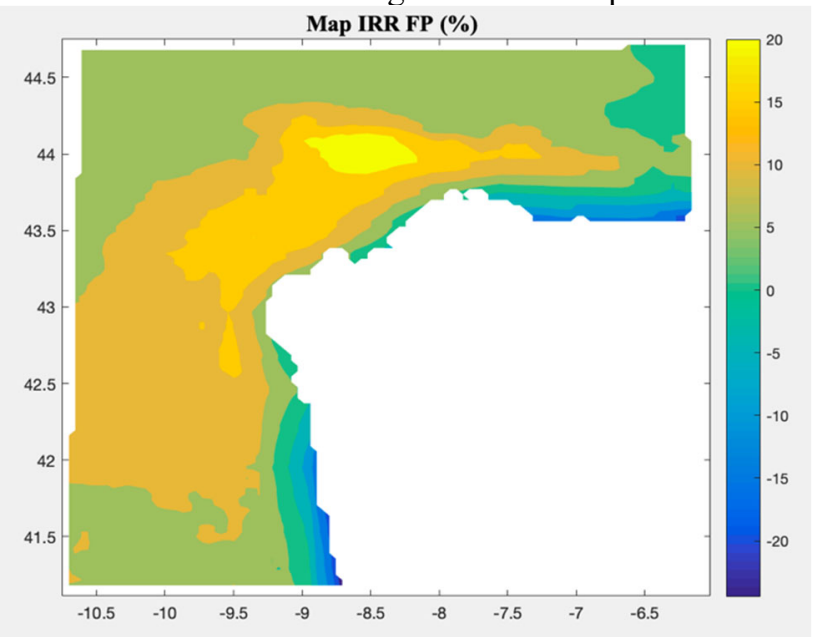

Fig. 5. IRR for Scenario 2.

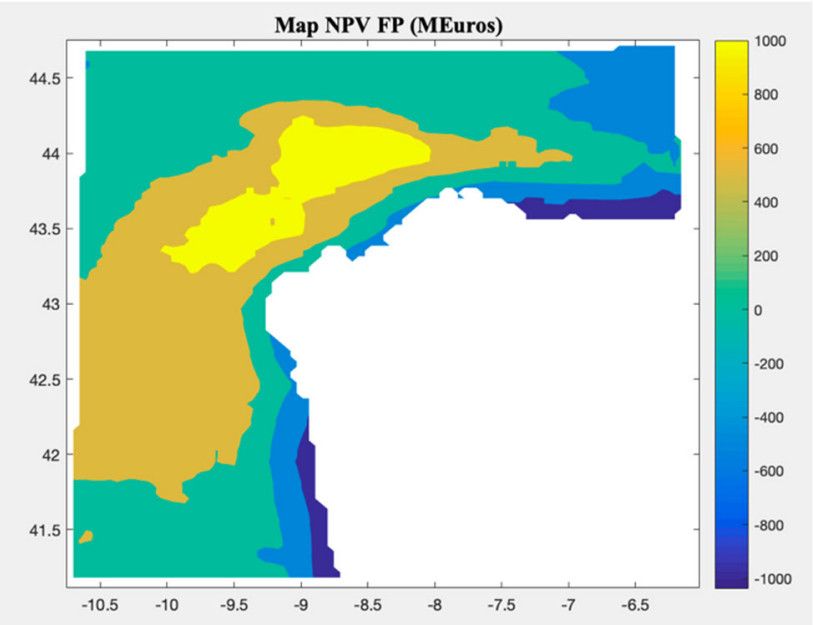

Fig. 6. NPV for Scenario 2.

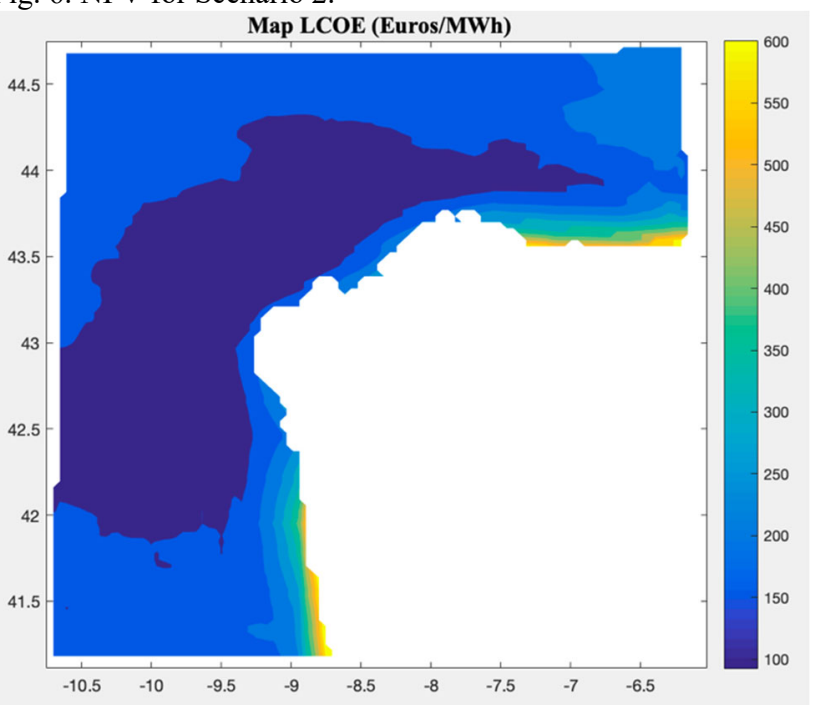

Fig. 7. LCOE for Scenario 2.

\subsection{SCENARIO 3}

Considering two types of floating offshore renewable energies (floating offshore wind and floating wave energy) at the same offshore farm, results go: from $-134.14 \%$ to $12.80 \%$ for IRR (see Fig. 8), from -1,338 M€ to 582.34 M€ for NPV (see Fig. 9) and from 137.19 €/MWh to 1,100
$€ / M W h$ for LCOE (see Fig. 10). Therefore, for the tariff considered, a floating offshore farm with independent arrays will be economically feasible for some regions where NPV is positive and where IRR is higher than the capital cost.

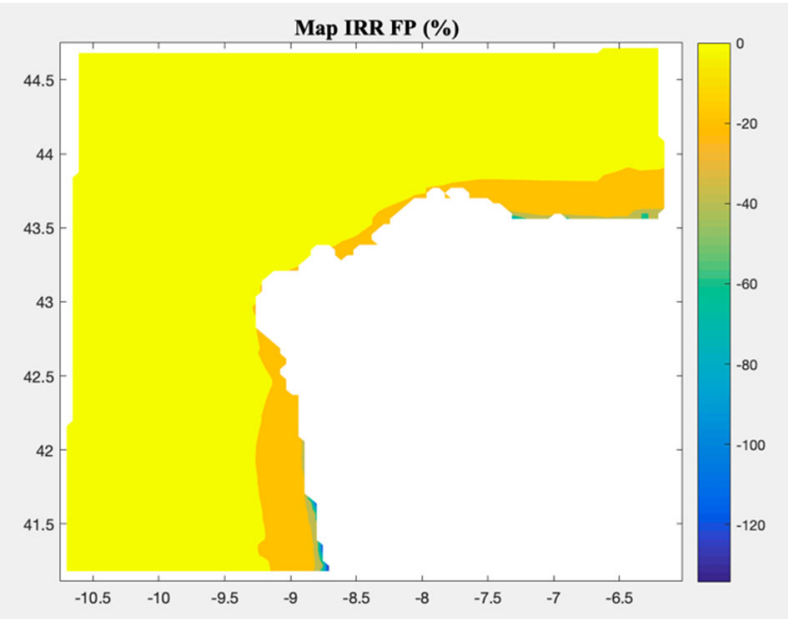

Fig. 8. IRR for Scenario 3.

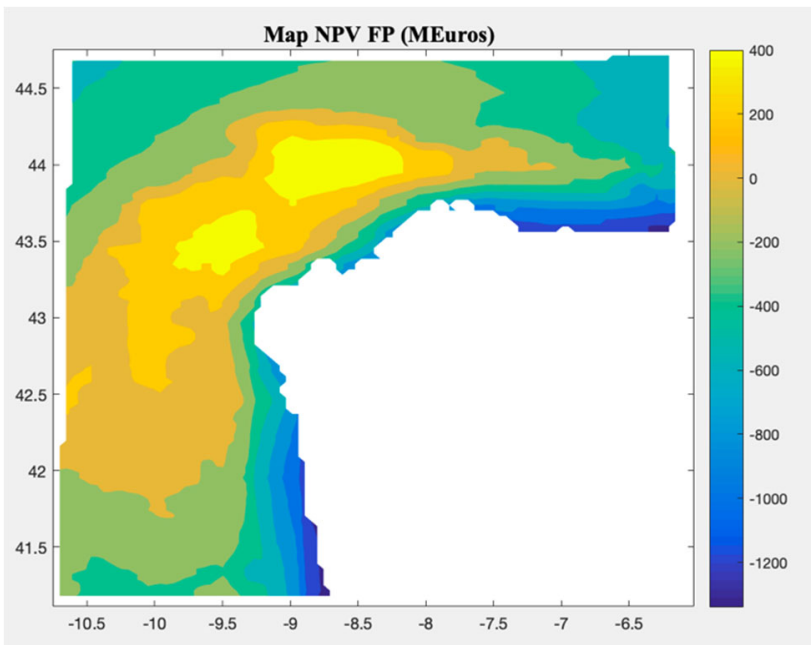

Fig. 9. NPV for Scenario 3.

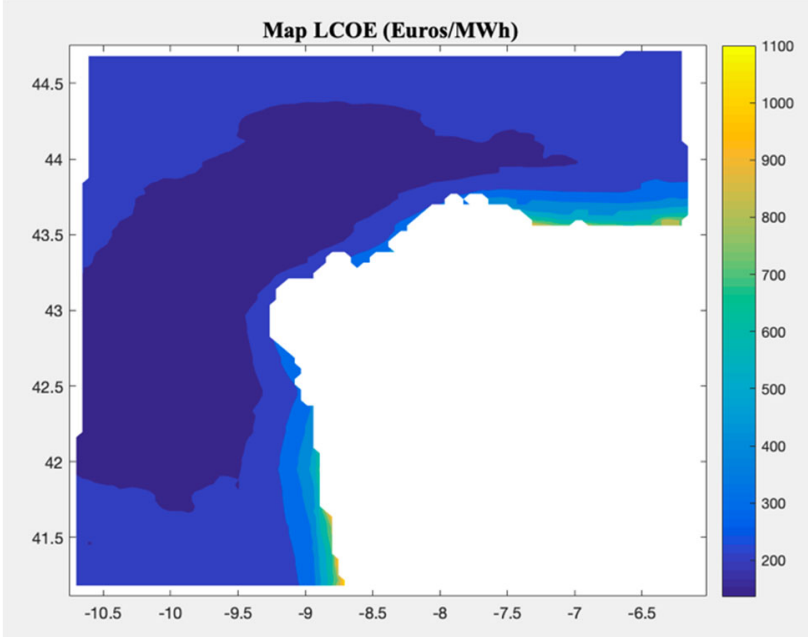

Fig. 10. LCOE for Scenario 3.

\subsection{COMPARISON}


Comparing the best results of IRR, NPV and LCOE for the three scenarios considered (see Table II), it is important to notice that offshore wind has better values than wave energy. However, if a mixed farm is built considering wave energy and offshore wind in an independent array, results will be better than the case of only wave energy. Therefore, the presence of floating offshore wind energy in an offshore renewable energy farm composed by wave energy converters improves its economic results, doing it more economically feasible.

Table II. - Comparison of the best values of IRR, NPV and LCOE for the three scenarios studied.

\begin{tabular}{|c|c|c|c|}
\hline SCENARIO & 1 & 2 & 3 \\
\hline $\begin{array}{c}\text { ENERGY } \\
\text { RESOURCE }\end{array}$ & Waves & $\begin{array}{c}\text { Offshore } \\
\text { Wind }\end{array}$ & $\begin{array}{c}\text { Waves + Offshore } \\
\text { Wind IA }\end{array}$ \\
\hline IRR (\%) & -110.36 & 22.21 & 12.80 \\
\hline NPV (M€) & $-1,895$ & 1,376 & 582.34 \\
\hline LCOE (€/MWh) & 759.25 & 92.69 & 137.19 \\
\hline
\end{tabular}

\section{Conclusion}

This paper has analysed the importance of independent arrays in offshore renewable energy farms.

In this context, three different scenarios have been contemplated for a floating offshore renewable energy farm: (1) only floating wave energy; (2) only floating offshore wind energy; and (3) both floating wave energy and floating offshore wind energy installed in independent arrays.

The article has suggested a technique to analyse the main economic parameters of these three scenarios and to analyse and decide their economic feasibility in terms of NPV, IRR and LCOE. All of them have been represented as maps of a particular location.

The case of study has studied a hypothetic offshore renewable energy farm located in the Galicia region (Spain), one of Spanish areas with great offshore renewable energy resources.

Results indicate which of the three scenarios has the best economic results, that is to use only offshore wind, followed by the use of floating offshore wind and wave energy with independent arrays and, finally, the wave energy, which is not economically feasible at this stage of development.

This document is helpful to compare different floating offshore renewable energy know-hows in economic terms and help to take decisions about this new developing sector in order to reconstruct the post-pandemic European regions.

\section{Acknowledgement}

This research was funded by Project PID2019-105386RAI00 "Design of a tool for the selection of offshore renewable energy locations and technologies: application to Spanish territorial waters (SEARENEW)", financed by Ministerio de Ciencia e Innovación - Agencia Estatal de Investigación/10.13039/501100011033

\section{References}

[1] United Nations Framework Convention on Climate Change, Paris Agreement, Paris (France), 2015.

[2] José A. Roca, El periódico de la Energía, Los Combust. Fósiles Represent. E1 80\% La Prod. y El Consum. Energía En EEUU. (2020). https://elperiodicodelaenergia.com/los-combustiblesfosiles-representan-el-80-de-la-produccion-y-elconsumo-de-energia-en-eeuu/ (accessed September 15, 2020).

[3] RTVE, Cambio Climático Las Renov. Superan Por Prim. Vez a Las Energías Fósiles En La Unión Eur. (2021). https://www.rtve.es/noticias/20210125/renovablessuperan-energias-fosiles-primera-vezue/2069200.shtml.

[4] Ember, EU Power Sector in 2020, England, 2020. https://ember-climate.org/project/eu-power-sector2020/.

[5] K. Aruga, M.M. Islam, A. Jannat, Effects of COVID19 on Indian Energy Consumption, Sustainability. 12 (2020) 5616. https://doi.org/10.3390/su12145616.

[6] Comisión Europea, Plan Recuper. Para Eur. (2020). https://ec.europa.eu/info/strategy/recovery-planeurope_es.

[7] Sun Power: An Introduction to the Applications of Solar Energy - J. C. McVeigh - Google Libros, (n.d.). https://books.google.es/books?hl=es\&lr=\&id=J5z3Ag AAQBAJ\&oi=fnd\&pg=PP1\&dq= sun + energy\&ots $=\mathrm{vK}$ WaCLbHR9\&sig=nz3MIuI3TqLPnvDZfSaOa7fIXOY $\# \mathrm{v}=$ onepage \& $\mathrm{q}=$ sun energy $\& \mathrm{f}=$ false $($ accessed February 24, 2021).

[8] Energy from the Sun on JSTOR, (n.d.). https://www.jstor.org/stable/24996939?seq=1\#metadat a_info_tab_contents (accessed February 24, 2021).

[9] A.M. Hamiche, A.B. Stambouli, S. Flazi, A review of the water-energy nexus, Renew. Sustain. Energy Rev. 65 (2016) 319-331.

https://doi.org/10.1016/j.rser.2016.07.020.

[10] J.K. Kaldellis, D. Zafirakis, The wind energy (r)evolution: A short review of a long history, Renew. Energy. 36 (2011) 1887-1901.

https://doi.org/https://doi.org/10.1016/j.renene.2011.01 .002 .

[11] G.M. Joselin Herbert, S. Iniyan, E. Sreevalsan, S. Rajapandian, A review of wind energy technologies, Renew. Sustain. Energy Rev. 11 (2007) 1117-1145. https://doi.org/10.1016/j.rser.2005.08.004.

[12] B. Drew, A.R. Plummer, M.N. Sahinkaya, A review of wave energy converter technology, (n.d.). https://doi.org/10.1243/09576509JPE782.

[13] Wieczorek A Negro S Harmsen R Heimeriks G Luo L et. al., A review of the European offshore wind innovation system, Renew. Sustain. Energy Rev. 26 (2013) 294-306.

www.sciencedirect.com/science/article/pii/S13640321 13003481.

[14] Y. Kumar, J. Ringenberg, S.S. Depuru, V.K. Devabhaktuni, J.W. Lee, E. Nikolaidis, B. Andersen, A. Afjeh, Wind energy: Trends and enabling technologies, Renew. Sustain. Energy Rev. 53 (2016). https://doi.org/10.1016/j.rser.2015.07.200.

[15] A. Uihlein, D. Magagna, Wave and tidal current energy - A review of the current state of research beyond technology, Renew. Sustain. Energy Rev. 58 (2016) 1070-1081. 
https://doi.org/10.1016/J.RSER.2015.12.284.

[16] L. Castro-Santos, A. Filgueira-Vizoso, L. Carral-Couce, J.Á.F. Formoso, Economic feasibility of floating offshore wind farms, Energy. (2016).

https://doi.org/10.1016/j.energy.2016.06.135.

[17] M. Seixas, R. Melício, V.M.F. Mendes, Simulation of rectifier voltage malfunction on OWECS, four-level converter, HVDC light link: Smart grid context tool, Energy Convers. Manag. 97 (2015) 140-153. https://doi.org/10.1016/j.enconman.2015.03.050.

[18] L. Castro-Santos, M.I. Lamas-Galdo, A. FilgueiraVizoso, Managing the oceans: Site selection of a floating offshore wind farm based on GIS spatial analysis, Mar. Policy. 113 (2020).

https://doi.org/10.1016/j.marpol.2019.103803.

[19] KENNETH PEIRE; HENDRIK NONNEMAN; ERIC BOSSCHEM, GRAVITY BASE FOUNDATIONS FOR THE THORNTON BANK OFFSHORE WIND FARM, Terra Aqua. 115 (2009) 11. https://www.iadcdredging.com/wp-content/uploads/2017/02/articlegravity-base-foundations-for-the-thornton-bankoffshore-wind-farm-115-3.pdf.

[20] L. Arany, S. Bhattacharya, J. Macdonald, S.J. Hogan, Design of monopiles for offshore wind turbines in 10 steps, Soil Dyn. Earthq. Eng. 92 (2017). https://doi.org/10.1016/j.soildyn.2016.09.024.

[21] A.A. Shittu, A. Mehmanparast, L. Wang, K. Salonitis, A. Kolios, Comparative study of structural reliability assessment methods for offshore wind turbine jacket support structures, Appl. Sci. 10 (2020). https://doi.org/10.3390/app10030860.

[22] K. Jessen, K. Laugesen, S. M. Mortensen, J. K. Jensen, M. N. Soltani, Experimental Validation of Aero-HydroServo-Elastic Models of a Scaled Floating Offshore Wind Turbine, Appl. Sci. 9 (2019) 1244. https://doi.org/10.3390/app9061244.

[23] M. Karimirad, C. Michailides, V-shaped semisubmersible offshore wind turbine: An alternative concept for offshore wind technology, Renew. Energy. 83 (2015) 126-143. https://doi.org/10.1016/J.RENENE.2015.04.033.

[24] A.J. Sabrina Dankelmann, Bart Visser, Neelabh Gupta, Jose Serna, Bernardino Counago, Alvaro Urruchi, Jose L. Fernández, Carlos Cortés, Raul Guanche Garcia, TELWIND- Integrated Telescopic tower combined with an evolved spar floating substructurefor low-cost deep water offshore wind and next generation of $10 \mathrm{MW}+$ wind turbines, 2016.

[25] N. Khan, A. Kalair, N. Abas, A. Haider, Review of ocean tidal, wave and thermal energy technologies, Renew. Sustain. Energy Rev. 72 (2017) 590-604. https://doi.org/10.1016/J.RSER.2017.01.079.

[26] International Renewable Energy Agency (IRENA), Wave Energy Technology Brief, 2014. https://doi.org/10.1016/B978-0-08-099424-6.00017-X.

[27] OWC Pico Plant, Web Page OWC Pico Plant, (2012).

[28] Sperboy, Sperboy Webpage, (2013).

[29] A. Weinstein, G. Fredrikson, M. Jane, P. Group, K.N.R. Denmark, AquaBuOY - The Offshore Wave Energy Converter Numerical Modeling and Optimization, in: IEEE, 2003: pp. 1854-1859. https://doi.org/10.1109/OCEANS.2003.178203.

[30] L. Castro-Santos, D. Silva, A.R. Bento, N. Salvação, C.G. Soares, Economic feasibility of wave energy farms in Portugal, Energies. 11 (2018) 1-16. https://doi.org/10.3390/en11113149.

[31] Wavebob, Wavebob Webpage, (2013).

[32] Pelamis, Pelamis wave power, (2012).

[33] D.J. Pizer, C. Retzler, R.M. Henderson, F.L. Cowieson, M.G. Shaw, B. Dickens, R. Hart, PELAMIS WEC -
RECENT ADVANCES IN THE NUMERICAL AND EXPERIMENTAL MODELLING PROGRAMME, in: $6^{\wedge}\{$ th $\}$ Eur. Wave Tidal Energy Conf., 2005.

[34] L. Castro-Santos, A. Filgueira-Vizoso, A Software for Calculating the Economic Aspects of Floating Offshore Renewable Energies, Int. J. Environ. Res. Public Health. 17 (2019) 19. https://doi.org/10.3390/ijerph17010218.

[35] IEA, The impact of the Covid-19 crisis on clean energy progress, Paris (France), 2020.

https://www.iea.org/articles/the-impact-of-the-covid19-crisis-on-clean-energy-progress.

[36] L. Castro-Santos, E. Martins, C. Guedes Soares, Economic comparison of technological alternatives to harness offshore wind and wave energies, Energy. 140 (2017). https://doi.org/10.1016/j.energy.2017.08.103.

[37] Instituto para la Diversificación y el Ahorro de la Energía (IDAE), Análisis del recurso. Atlas eólico de España. Estudio técnico. PER 2011-2020, Madrid, 2011.

[38] Navantia, Navantia web page, (2019).

[39] Pelamis Wave Power, Pelamis Webpage, (2013).

[40] A. Aubault, C. Cermelli, D. Roddier, Windfloat: a floating foundation for offshore wind turbines. Part III: Structural analysis, in: ASME 28th Int. Conf. Ocean. Offshore Arct. Eng. OMAE2009, Honolulu, Hawaii (USA), 2009: pp. 1-8.

[41] S. Astariz, G. Iglesias, Accessibility for operation and maintenance tasks in co-located wind and wave energy farms with non-uniformly distributed arrays, Energy Convers. Manag. 106 (2015) 1219-1229. https://doi.org/10.1016/j.enconman.2015.10.060. 